\title{
4CMenB Immunization Induces Serum Bactericidal Antibodies Against Non-Serogroup B Meningococcal Strains in Adolescents
}

\author{
Alessia Biolchi · Sara Tomei - Brunella Brunelli • Maria Giuliani · \\ Stefania Bambini · Ray Borrow · Heike Claus • Maria Cecilia O. Gorla • \\ Eva Hong · Ana Paula S. Lemos · Jay Lucidarme · Muhamed-Kheir Taha • \\ Ulrich Vogel · Sonia Budroni · Marzia M. Giuliani · Rino Rappuoli • \\ Philip Boucher · Mariagrazia Pizza iD \\ Received: September 24, 2020 / Accepted: October 31, 2020 / Published online: November 13, 2020 \\ (c) The Author(s) 2020
}

\section{ABSTRACT}

Introduction: Invasive meningococcal disease (IMD) is an important public health concern. In developed countries, most IMD is caused by meningococcal serogroup B (MenB) and two protein-based MenB vaccines are currently available: the four-component vaccine $4 \mathrm{CMenB}$ (Bexsero, GSK) and the bivalent vaccine MenBFHbp (Trumenba, Pfizer). Genes encoding the $4 \mathrm{CMenB}$ vaccine antigens are also present in

A. Biolchi · S. Tomei - B. Brunelli · M. Giuliani .

S. Bambini · S. Budroni - M. M. Giuliani ·

R. Rappuoli · M. Pizza ( $ه)$

GSK, Siena, Italy

e-mail: mariagrazia.x.pizza@gsk.com

R. Borrow $\cdot$ J. Lucidarme

Meningococcal Reference Unit, Public Health

England, Manchester Royal Infirmary, Manchester, UK

H. Claus · U. Vogel

Institute for Hygiene and Microbiology, University of Würzburg, Würzburg, Germany

M. C. O. Gorla · A. P. S. Lemos

Adolfo Lutz Institute, São Paulo, Brazil

E. Hong · M.-K. Taha

Institut Pasteur, Paris, France

P. Boucher

PRA Health Sciences C/O GSK, Fort Washington, PA, USA strains belonging to other meningococcal serogroups.

Methods: To evaluate the potential of $4 \mathrm{CMenB}$ vaccination to protect adolescents against nonMenB IMD, we tested the bactericidal activity of sera from immunized adolescents on 147 (127 European and 20 Brazilian) non-MenB IMD isolates, with a serum bactericidal antibody assay using human complement (hSBA). Serum pools were prepared using samples from randomly selected participants in various clinical trials, pre- and post-vaccination: 12 adolescents who received two doses of 4 CMenB 2 months apart, and 10 adolescents who received a single dose of a MenACWY conjugate vaccine (as positive control).

Results: 4CMenB pre-immune sera killed 7.5\% of the 147 non-MenB isolates at hSBA titers $\geq 1: 4$. In total, $91(61.9 \%)$ tested isolates were killed by post-dose 2 pooled sera at hSBA titers $\geq 1: 4$, corresponding to $44 / 80$ (55.0\%) MenC, 26/35 (74.3\%) MenW, and 21/32 (65.6\%) MenY isolates killed.

Conclusion: 4CMenB vaccination in adolescents induces bactericidal killing of non-MenB isolates, suggesting that mass vaccination could impact IMD due to serogroups other than MenB.

Keywords: 4CMenB; Cross-protection; Meningococcal vaccine; Non-MenB strains; Serum bactericidal antibody activity 


\section{Key Summary Points}

\section{Why carry out this study?}

The $4 \mathrm{CMenB}$ vaccine (Bexsero, GSK) was developed to protect against invasive meningococcal disease (IMD) caused by serogroup B Neisseria meningitidis. As 4CMenB antigens are also commonly found in other meningococcal serogroups, 4 CMenB may offer protection against non-B serogroups causing IMD.

We investigated if $4 \mathrm{CMenB}$ vaccination can raise a functional immune response against non-B serogroup strains in adolescents, one of the populations most susceptible to meningococcal disease.

\section{What was learned from the study?}

We showed that the antibodies induced by vaccination of adolescents with 4CMenB induce bactericidal killing against $N$. meningitidis $\mathrm{C}, \mathrm{W}$, and $\mathrm{Y}$, by using a large panel of 147 non-B isolates representative of current IMD epidemiology.

While 4CMenB was developed to protect against $N$. meningitidis serogroup $B$, the immune responses observed in sera from adolescents vaccinated with $4 \mathrm{CMenB}$ suggest protection against non-B serogroups as well.

These results expand earlier findings and support previous evidence that $4 \mathrm{CMenB}$ vaccination may have the added value of cross-protection against prevalent IMDcausing $N$. meningitidis serogroup $\mathrm{C}, \mathrm{W}$, and $\mathrm{Y}$ strains.

\section{DIGITAL FEATURES}

This article is published with digital features, including a summary slide, to facilitate understanding of the article. To view digital features for this article go to https://doi.org/10.6084/ m9.figshare.13169279.

\section{INTRODUCTION}

Even though an increasing number of countries are implementing meningococcal vaccination programs, invasive meningococcal disease (IMD) remains a major public health concern. While rare in high-income countries, IMD has serious consequences, with up to one-third of survivors experiencing long-term or permanent sequelae, and case fatality rates of $10-15 \%$ even if the correct treatment is administered [1]. Six serogroups of the disease-causing pathogen, Neisseria meningitidis, account together for more than $99 \%$ of IMD cases: meningococcal serogroup (Men) A, MenB, MenC, MenW, MenX, and MenY [2]. The large strain diversity, particularly as far as MenB is concerned, together with an ever-evolving and unpredictable IMD epidemiology make the concept of a universal meningococcal vaccine virtually impossible. To date, there are no licensed vaccines against MenX, but capsular polysaccharide conjugate MenA, MenC, MenCY (as part of a combination vaccine) and MenACWY vaccines have been available for more than two decades and their use has considerably reduced the prevalence of these serogroups in countries recommending vaccination [1, 3]. Consequently, with MenB becoming prominent in several regions worldwide and especially in high-income countries [4], vaccines against this serogroup were developed. The MenB capsular polysaccharide is poorly immunogenic, and therefore, MenB vaccines were designed to contain N. meningitidis subcapsular surface-exposed proteins as antigenic components. Two vaccines with broad protection against MenB strains, 4CMenB (Bexsero, GSK) [5] and MenB-FHbp (rLP2086, Trumenba, Pfizer) [6] are licensed for use in several countries worldwide. $4 \mathrm{CMenB}$ is a fourcomponent MenB vaccine formulation containing the Neisseria adhesin A (NadA), factor $\mathrm{H}$ binding protein (fHbp), and the neisserial heparin binding antigen (NHBA), in combination with outer membrane vesicles (OMV) from a New Zealand outbreak strain, expressing 
porin A protein (PorA) P1.4 [5]. The vaccine is licensed for use against MenB-caused IMD in individuals $10-25$ years of age in the USA and from 2 months of age in Europe and several countries worldwide. Men-FHbp is a bivalent fHbp vaccine licensed in individuals 10-25 years of age in the USA and from 10 years of age in Europe [7]. The UK was the first country to implement a vaccination program against MenB in 2015 using 4CMenB, with an already noticeable impact on MenB-caused IMD incidence [8]. MenB vaccines contain antigen components that are present across the diverse $N$. meningitidis strains and serogroups, and even other Neisseria species. Therefore, they may exhibit cross-protection against various meningococcal serogroups. Some indications already exist that 4CMenB and Men-FHbp may exhibit cross-protection against serogroups other than those targeted [9-12].

We previously reported that pooled sera from infants immunized with 4CMenB exhibit serum bactericidal activity against non-MenB strains, with 109 out of 147 strains (74.1\%) of MenC, MenW, and MenY clinical isolates from Europe and Brazil being killed by sera collected from infants immunized with the $4 \mathrm{CMenB}$ vaccine [13]. Here, we describe the bactericidal activity of adolescent post-vaccination sera measured by serum bactericidal antibody assay using human complement (hSBA) against nonMenB strains selected from the same panels of European and Brazilian IMD isolates.

\section{METHODS}

\section{Meningococcal Isolates: Euro-3 Panel and Brazilian Panel}

The non-MenB isolates were previously described in detail [13]. Briefly, isolates belonged to two panels: one containing 227 isolates collected from England and Wales, Germany, and France (Euro-3 panel) between July 2007 and June 2008, and one consisting of 41 Brazilian isolates collected in the year 2012. All isolates were invasive non-MenB disease isolates originating from meningitis and/or septicemia and were isolated from cerebrospinal fluid or blood samples. The Euro-3 panel included mostly MenC (130, 57\%), MenW (36, 16\%), and MenY $(50,22 \%)$ isolates; other isolates were MenA, MenE, MenZ, and non-groupable. The Brazilian panel consisted of five (12\%) MenC, 16 (39\%) MenW, and 20 (49\%) MenY isolates. All isolates were characterized by multilocus sequence typing [13].

From these panels, 147 MenC, MenW, and MenY isolates (127 from the Euro-3 panel and 20 from the Brazilian panel) were selected for testing by hSBA. In the Euro-3 panel, an initial random, unbiased selection was applied. Adequate representation in terms of genetic diversity and antigenic profiles for each serogroup was afterwards confirmed by statistical evaluation. Brazilian isolates were selected on the basis of their epidemiological relevance in the region, with no further support of statistical analysis. The distribution of isolates in both panels according to $4 \mathrm{CMenB}$ antigen genotypes is presented in Fig. 1 [13].

\section{Immunogenicity Assessment}

The hSBA assay was performed following an established protocol [14] with minor modifications, as previously described [13].

Serum pools were prepared using pre- and post-vaccination samples from participants in various clinical trials. Sera from 12 randomly selected adolescents out of 342 originally included in the per protocol set, aged 11-17 years from Chile, who received two doses of $4 \mathrm{CMenB}$ 2 months apart (as part of a three-dose course; NCT00661713 [15]) were collected before vaccination and 1 month after the second vaccination. Two different pools of 12 adolescents were used for the analysis of the EU strain panel and Brazilian panel, respectively.

Pooled sera from 10 randomly selected adolescents who received a single dose of a MenACWY conjugate vaccine (Menveo, GSK) in a previous clinical trial (NCT00518180 [16]) were used as positive control to confirm that bactericidal killing of the strains is induced by vaccination with the vaccine containing the capsular polysaccharides of MenC, MenW, and MenY. The sera were pooled separately for the 

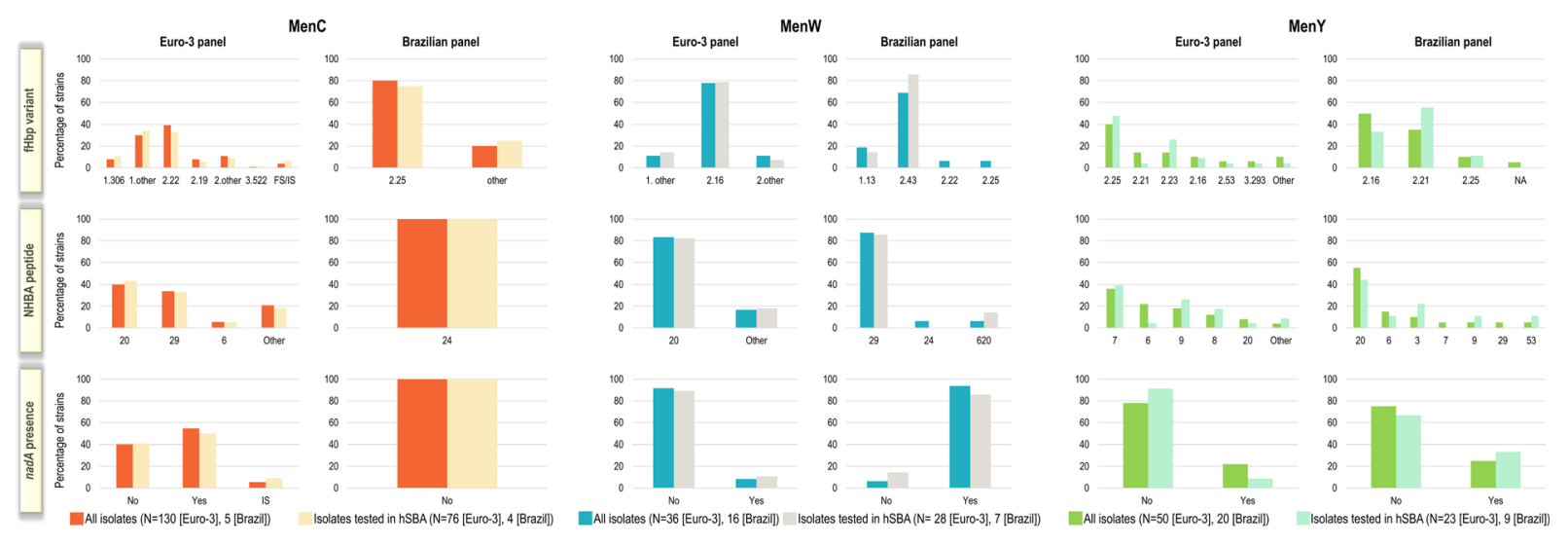

Fig. 1 Distribution of $4 \mathrm{CMenB}$ antigen genotypes by serogroup in isolates available for testing compared to the subsets of isolates tested in hSBA (data from Biolchi et al. [13]). hSBA serum bactericidal antibody assay using human complement, Men meningococcal serogroups, $\mathrm{fHbp}$ factor $\mathrm{H}$ binding protein, FS/IS frameshift/insertion

pre-vaccination and 1 month post-vaccination time points.

The number and percentage of isolates killed at different titers were tabulated at each time point by serogroup, panel, and overall.

\section{Ethics}

Studies NCT00661713 and NCT00518180 were conducted in accordance with the Declaration of Helsinki. The use of samples was based upon written informed consent obtained from the parents/guardians of the adolescents before the study-specific procedures. However, for a subset of participants in study NCT00661713, the collected informed consent did not include permission for reuse of the biological samples (some of which were used in the current study). Upon discovery of the unintended error, GSK informed the principal investigators, the local ethics committee, and the Ministry of Health of the concerned country and notified all impacted participants.

\section{RESULTS}

When tested against the $147 \mathrm{MenC}$, MenW, and MenY isolates, $4 \mathrm{CMenB}$ pre-immune sera from sequence-disrupted gene, NA not available, NHBA neisserial heparin binding antigen, nadA Neisseria adhesin $A$ gene, $\mathrm{N}$ number of (tested) isolates in each panel

adolescents killed $7.5 \%$ of isolates (hSBA titers $\geq 1: 4$ ).

Sera from immunized adolescents killed 91 (61.9\%) of the 147 tested isolates, with hSBA titers ranging from $\geq 1: 4$ to $\geq 1: 128$. Of the tested 127 isolates from the Euro-3 panel, 40/76 (52.6\%), 20/28 (71.4\%), and 15/23 (65.2\%) MenC, MenW, and MenY isolates were killed by sera from vaccinated adolescents, at hSBA titers $\geq 1: 4$ (Table 1, Fig. 2). Of the tested 20 isolates from the Brazilian panel, 4/4 (100\%) MenC isolates, 6/7 (85.7\%) MenW isolates, and 6/9 $(66.7 \%)$ MenY isolates were killed at hSBA titers $\geq 1: 4$ by post-vaccination adolescent sera (Table 1, Fig. 2).

Of the tested isolates from the European panel, all strains were killed by MenACWY-immune sera at hSBA titers $\geq 1: 64$ for MenC, $\geq 1: 128$ for MenW and $\geq 1: 256$ for MenY. Of the tested isolates from the Brazilian panel, all strains were killed by MenACWY-immune sera at $\mathrm{hSBA}$ titers $\geq 1: 128$ for $\mathrm{MenC}, \geq 1: 64$ for MenW, and $\geq 1: 512$ for MenY.

\section{DISCUSSION}

Pooled sera from adolescents immunized with two doses of 4CMenB induced bactericidal killing of 91 out of 147 tested isolates 
Table 1 Number and percentage of non-MenB isolates killed in hSBA by adolescent 4CMenB-elicited immune sera at different bactericidal titers in the Euro-3 and Brazilian panels, by serogroup and time point

\begin{tabular}{|c|c|c|c|c|c|c|c|c|}
\hline \multirow[t]{2}{*}{ hSBA titers } & \multicolumn{2}{|l|}{ MenC } & \multicolumn{2}{|l|}{ MenW } & \multicolumn{2}{|l|}{ MenY } & \multicolumn{2}{|l|}{ All } \\
\hline & Pre-vac & $\overline{\text { Post-vac }}$ & Pre-vac & $\overline{\text { Post-vac }}$ & $\overline{\text { Pre-vac }}$ & $\overline{\text { Post-vac }}$ & $\overline{\text { Pre-vac }}$ & $\overline{\text { Post-vac }}$ \\
\hline Euro-3 panel & $N=76$ & & $\mathrm{~N}=28$ & & $\mathrm{~N}=23$ & & $\mathrm{~N}=127$ & \\
\hline$\geq 1: 4$ & $2(2.6)$ & $40(52.6)$ & $4(14.3)$ & $20(71.4)$ & $5(21.7)$ & $15(65.2)$ & $11(8.7)$ & $75(59.1)$ \\
\hline$\geq 1: 8$ & $0(0.0)$ & $33(43.4)$ & $3(10.7)$ & $20(71.4)$ & $3(13.0)$ & $15(65.2)$ & $6(4.7)$ & $68(53.5)$ \\
\hline$\geq 1: 16$ & $0(0.0)$ & $28(36.8)$ & $3(10.7)$ & $20(71.4)$ & $2(8.7)$ & $14(60.9)$ & $5(3.9)$ & $62(48.8)$ \\
\hline$\geq 1: 32$ & $0(0.0)$ & $25(32.9)$ & $2(7.1)$ & $19(67.9)$ & $1(4.3)$ & $9(39.1)$ & $3(2.4)$ & $53(41.7)$ \\
\hline$\geq 1: 64$ & $0(0.0)$ & $23(30.3)$ & $1(3.6)$ & $15(53.6)$ & $1(4.3)$ & $6(26.1)$ & $2(1.6)$ & $44(34.6)$ \\
\hline$\geq 1: 128$ & $0(0.0)$ & $17(22.4)$ & $0(0.0)$ & $12(42.9)$ & $1(4.3)$ & $2(8.7)$ & $1(0.8)$ & $31(24.4)$ \\
\hline Brazilian panel & $N=4$ & & $\mathrm{~N}=7$ & & $\mathrm{~N}=9$ & & $\mathrm{~N}=20$ & \\
\hline$\geq 1: 4$ & $0(0.0)$ & $4(100)$ & $0(0.0)$ & $6(85.7)$ & $0(0.0)$ & $6(66.7)$ & $0(0.0)$ & $16(80.0)$ \\
\hline$\geq 1: 8$ & $0(0.0)$ & $4(100)$ & $0(0.0)$ & $6(85.7)$ & $0(0.0)$ & $6(66.7)$ & $0(0.0)$ & $16(80.0)$ \\
\hline$\geq 1: 16$ & $0(0.0)$ & $4(100)$ & $0(0.0)$ & $5(71.4)$ & $0(0.0)$ & $6(66.7)$ & $0(0.0)$ & $15(75.0)$ \\
\hline$\geq 1: 32$ & $0(0.0)$ & $3(75.0)$ & $0(0.0)$ & $5(71.4)$ & $0(0.0)$ & $6(66.7)$ & $0(0.0)$ & $14(70.0)$ \\
\hline$\geq 1: 64$ & $0(0.0)$ & $0(0.0)$ & $0(0.0)$ & $5(71.4)$ & $0(0.0)$ & $6(66.7)$ & $0(0.0)$ & $11(55.0)$ \\
\hline$\geq 1: 128$ & $0(0.0)$ & $0(0.0)$ & $0(0.0)$ & $5(71.4)$ & $0(0.0)$ & $4(44.4)$ & $0(0.0)$ & $9(45.0)$ \\
\hline
\end{tabular}

Data are presented as number and percentage of isolates killed in hSBA at the indicated titer

Men meningococcal serogroup, $h S B A$ serum bactericidal antibody assay using human complement, $N$ number of strains tested in hSBA with the $4 \mathrm{CMenB}$-elicited immune sera, pre-vac pre-vaccination, post-vac post-vaccination (post-dose 2)

representative of genetic and geographic diversity of MenC, MenW, and MenY strains in England and Wales, Germany, France, and Brazil, resulting in an overall strain coverage of approximately $62 \%$. These data complement our previous findings, which showed that sera of infants vaccinated with four $4 \mathrm{CMenB}$ doses afforded a coverage of $74 \%$ of the tested nonMenB strains [13]. It is important to note that the difference in coverage between infant and adolescent sera is related mainly to MenY strains (93.8\% [13] versus 65.6\%). This effect could be due to differences in the bactericidal assay, based on not heat-inactivated sera in the case of infants, which could result in a higher amount of active complement and, in turn, in higher bactericidal titers, particularly in the case of MenY strains [17].

The 4CMenB antigenic components are known to be present and surface-exposed on non-MenB strains as well. Variants of fHbp are present in nearly all IMD-causing strains, albeit at different levels of expression [18] and across some neisserial commensal species [19-21]. fHbp is present, but not surface-exposed in Neisseria gonorrhoeae [22]. The $n h b A$ gene is also present in all meningococci as well as in pathogenic (N.gonorrhoeae) and commensal Neisseria species, such as Neisseria lactamica, Neisseria polysaccharea, or Neisseria flavescens [21]. The nadA gene is harbored by approximately $25 \%$ of meningococci [23], although this was shown to vary geographically and over time 


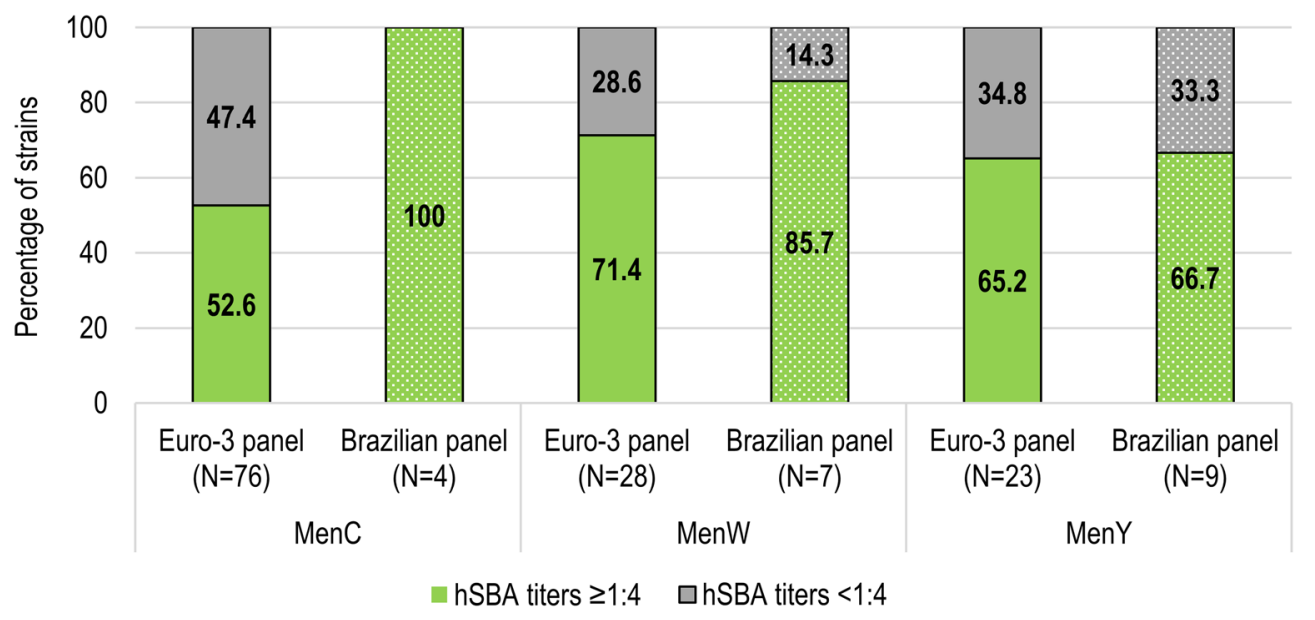

Fig. 2 Percentage of non-MenB isolates killed in hSBA by adolescent $4 \mathrm{CMenB}$-elicited immune sera in the Euro-3 panel and the Brazilian panel. Men meningococcal

serogroups, hSBA serum bactericidal antibody assay using human complement, $\mathrm{N}$ number of tested isolates in each panel

[24]. The results of the current study indicate that coverage of $4 \mathrm{CMenB}$ is not limited to MenB strains, since more than half of strains across all serogroups in each panel were killed by immune sera in hSBA. Indeed, among the total 268 isolates in both panels, $38 \%$ of MenC strains carried fHbp variant 1 peptides, the majority presented NHBA peptides 20, 24, and 29, and $55 \%$ harbored the nadA gene [13]. In contrast, PorA P1.4 was only present in one MenY isolate from the Brazilian panel [13]. Antigen genotyping showed differences between the MenC isolates in the two panels, including the isolates tested in hSBA. Variant 2 fHbp peptides were detected for more than $75 \%$ of strains in the Brazilian panel, but only half of the European strains. Moreover, the NHBA peptides differed from one panel to another and Brazilian MenC strains did not carry the nadA gene. Nevertheless, $52.6 \%$ (in the Euro-panel) and 100\% (in the Brazilian panel) of tested MenC isolates were killed in hSBA, indicating that multiple 4CMenB antigens are accessible for antibody binding in the MenC strains. The most likely bactericidal antigen for MenW and MenY strains was NHBA, while NadA could play a key role in killing of Brazilian MenW isolates [13]. Similarly, cross-protective antibodies induced by $4 \mathrm{CMenB}$ against a MenW sequence type 11 clonal complex strain circulating in England

and Wales during 2011-2012 were previously attributed to the NHBA and NadA antigens [12].

Pooled sera from 4CMenB-vaccinated infants, adolescents, and adults displayed bactericidal killing in hSBA, at different titers, against nine of 11 MenX isolates collected between 1995 and 2007 from Africa and France [11]. Neither of the two isolates from France, which were genetically different from the African ones, were killed by the pooled infant sera [11].

Of note, the use of hSBA performed on pooled $4 \mathrm{CMenB}$ immune sera has been previously shown to predict individual protection against MenB for infants and toddlers [25].

This study represents the first example in which a large panel of 147 non-B isolates has been analyzed in the serum hSBA assay with $4 \mathrm{CMenB}$ post-vaccination adolescent sera. A recent study also evaluated hSBA killing induced by sera from Men-FHbp-immunized individuals against six non-MenB strains (one MenA, MenC, MenX, and MenY and two MenW isolates), selected from a total of 292 isolates from the USA, England and Wales, the Netherlands, and Africa. Bactericidal activity was evaluated using individual serum samples collected from 30 adolescents aged 10-12 years and expressed as the percentage of adolescents with positive bactericidal titers [9]. Response rates 
after three MenB-FHbp doses were at least 83\% for the five MenC, MenW, MenX, and MenY isolates and 28\% for the MenA strain. However, the limited number of isolates analyzed in this study did not allow one to predict the potential of MenB-FHbp immune sera to cover the overall diversity of non-MenB strains carrying fHbp with a different sequence and/or expressed at different levels. The comparison between $4 \mathrm{CMenB}$ and Men-FHbp is hindered by the differences in study design, in the geographical and temporal provenance of the strains, and more importantly in the number of strains analyzed. However, both studies suggest that the two MenB vaccines provide coverage of meningococcal strains extending beyond the targeted serogroup.

This study has some potential limitations. The number of serum samples $(n=12)$ to be pooled for each time point was relatively small. In addition, since the tested IMD strains were collected from Europe and Brazil, it is difficult to extrapolate these results to other regions. However, in view of the genetic features of isolates already well described (e.g., by molecular epidemiology data deposited at the PubMLST Neisseria website [26], similar cross-protection against a large proportion of non-MenB isolates circulating worldwide can be expected.

\section{CONCLUSION}

Sera from 4CMenB-immunized adolescents induced bactericidal killing of 91 out of 147 tested non-MenB strains, corresponding to a coverage of $62 \%$ of non-MenB isolates. This suggests that mass vaccination using $4 \mathrm{CMenB}$ could also impact the burden of non-MenB IMD, although real-world evidence is still needed to confirm this hypothesis.

\section{ACKNOWLEDGEMENTS}

The authors would like to thank Gabriella De Angelis, Maurizio Comanducci and Monica Moschioni for their contributions to this study.
Trademarks. Bexsero and Menveo are trademarks owned by or licensed to the GSK group of companies. Trumenba is a trademark of Wyeth LLC (marketed by Pfizer Inc.).

Funding. This study was sponsored by Novartis Vaccines and Diagnostics, Inc., now part of the GSK group of companies. GlaxoSmithKline Biologicals SA took responsibility for all costs associated with the development and funded the journal's Rapid Service Fees. The German NRL is supported by the Robert Koch-Institute with funds from the Federal Ministry of Health (funding code 1369-237).

Medical Writing, Editorial, and Other Assistance. Authors thank the Modis platform for editorial assistance and manuscript coordination, on behalf of GSK. Petronela M. Petrar provided medical writing support and Divya Kesters coordinated the manuscript development and provided editorial support.

Authorship. All named authors meet the International Committee of Medical Journal Editors (ICMJE) criteria for authorship for this article, take responsibility for the integrity of the work as a whole, and have given their approval for this version to be published.

Authorship Contributions. AB, BB, ST performed the bactericidal assays and contributed to data analysis. SB, MG and MMG contributed to the analysis of the genetic data. MCOG, APSL, HC, UV, MKT, EH, RB and JL provided the isolates, genotyping and phenotyping data and contributed to data discussion. SoB performed the statistical analysis, MMG and RR contributed to the data interpretation and discussion, MP and $\mathrm{PB}$ designed the study and wrote the manuscript.

Prior Presentation. This manuscript is based on work that has been previously presented: The 37th Meeting of the European Society for Paediatric Infectious Diseases, Ljubljana, Slovenia, May 6-11, 2019: M. Pizza, A. Biolchi, G. De Angelis, M. Moschioni, S. Tomei, B. Brunelli, M. Giuliani, S. Bambini, R. Borrow, H. Claus, M.C. 
Outeiro Gorla, E. Hong, A.P. Silva de Lemos, J. Lucidarme, M.K. Taha, U. Vogel, M. Comanducci, S. Budroni, M.M. Giuliani, R. Rappuoli, P. Boucher, 4CMenB, a multicomponent meningococcal vaccine developed for serogroup B meningococci, elicits cross-reactive immunity against serogroups $\mathrm{C}, \mathrm{W}$ and $\mathrm{Y}(\mathrm{Ab}$ stract 0255). The 15th Meeting of the European Meningococcal and Haemophilus Disease Society, Lisbon, Portugal, May 27-30 2019: A. Biolchi, G. De Angelis, M. Moschioni, S. Tomei, B. Brunelli, M. Giuliani, S. Bambini, R. Borrow, H. Claus, M.C. Outeiro Gorla, E. Hong, A.P. Silva de Lemos, J. Lucidarme, M.K. Taha, U. Vogel, M. Comanducci, S. Budroni, M.M. Giuliani, R. Rappuoli, P. Boucher, M. Pizza, 4CMenB, a multicomponent meningococcal vaccine developed for serogroup B meningococci, elicits cross-reactive immunity against serogroups $\mathrm{C}$, $\mathrm{W}$ and Y (OC-EMGM2019-13221). The Meningitis Research Foundation Conference 2019, London, UK, November 5-6 2019: M. Pizza, G. De Angelis, M. Moschioni, S. Tomei, B. Brunelli, M. Giuliani, S. Bambini, R. Borrow, H. Claus, M.C. Outeiro Gorla, E. Hong, A.P. Silva de Lemos, J. Lucidarme, M.K. Taha, U. Vogel, M. Comanducci, S. Budroni, M.M. Giuliani, R. Rappuoli, P. Boucher, A. Biolchi, 4CMenB, a multicomponent meningococcal vaccine developed for serogroup B meningococci, elicits cross-reactive immunity against serogroups $\mathrm{C}$, $\mathrm{W}$ and $\mathrm{Y}$ (Abstract P12).

Disclosures. Alessia Biolchi, Sara Tomei, Brunella Brunelli, Maria Giuliani, Stefania Bambini, Sonia Budroni, Marzia M. Giuliani, Rino Rappuoli and Mariagrazia Pizza are employees of the GSK groups of companies. Sonia Budroni has a patent pending (WO 2015014922 A2). Philip Boucher is an employee of PRA Health Sciences c/o GSK. MuhamedKheir Taha received grants from Pfizer and the GSK group of companies and has a patent issued (630133). Jay Lucidarme and Ray Borrow have performed contract research on behalf of Public Health England for the GSK group of companies, Pfizer, and Sanofi Pasteur. Ana Paula S. Lemos reports personal fees from Pfizer and
Sanofi-Pasteur. Heike Claus and Ulrich Vogel 's institution received research grants from Novartis. Maria Cecilia O. Gorla and Eva Hong have nothing to disclose.

Compliance with Ethics Guidelines. Studies NCT00661713 and NCT00518180 were conducted in accordance with the Declaration of Helsinki. The use of samples was based upon written informed consent obtained from the parents/guardians of the adolescents before the study-specific procedures. However, for a subset of participants in study NCT00661713, the collected informed consent did not include permission for reuse of the biological samples (some of which were used in the current study). Upon discovery of the unintended error, GSK informed the principal investigators, the local ethics committee, and the Ministry of Health of the concerned country and notified all impacted participants.

Data Availability. To request access to patient-level data and documents for this study, please submit an enquiry via www. clinicalstudydatarequest.com.

Open Access. This article is licensed under a Creative Commons Attribution-NonCommercial 4.0 International License, which permits any non-commercial use, sharing, adaptation, distribution and reproduction in any medium or format, as long as you give appropriate credit to the original author(s) and the source, provide a link to the Creative Commons licence, and indicate if changes were made. The images or other third party material in this article are included in the article's Creative Commons licence, unless indicated otherwise in a credit line to the material. If material is not included in the article's Creative Commons licence and your intended use is not permitted by statutory regulation or exceeds the permitted use, you will need to obtain permission directly from the copyright holder. To view a copy of this licence, visit http://creativecommons.org/licenses/by$\mathrm{nc} / 4.0 /$. 


\section{REFERENCES}

1. Meningococcal vaccines: WHO position paper, November 2011. Wkly Epidemiol Rec. 2011;86(47): 521-39.

2. Acevedo R, Bai X, Borrow R, et al. The global meningococcal initiative meeting on prevention of meningococcal disease worldwide: epidemiology, surveillance, hypervirulent strains, antibiotic resistance and high-risk populations. Exp Rev Vacc. 2019;18(1):15-30.

3. World Health Organization. WHO position paper, meningococcal a conjugate vaccine: updated guidance, February 2015. Vaccine. 2018;36(24):3421-2.

4. Purmohamad A, Abasi E, Azimi T, et al. Global estimate of Neisseria meningitidis serogroups proportion in invasive meningococcal disease: a systematic review and meta-analysis. Microb Pathog. 2019;134:103571.

5. Rappuoli R, Pizza M, Masignani V, Vadivelu K. Meningococcal B vaccine (4CMenB): the journey from research to real world experience. Exp Rev Vacc. 2018;17(12):1111-21.

6. Perez JL, Absalon J, Beeslaar J, et al. From research to licensure and beyond: clinical development of MenB-fHbp, a broadly protective meningococcal B vaccine. Exp Rev Vacc. 2018;17(6):461-77.

7. Parikh S, Campbell H, Bettinger JA, et al. The everchanging epidemiology of meningococcal disease worldwide and the potential for prevention through vaccination. J Infect. 2020;81(4):483-98.

8. Ladhani SN, Andrews N, Parikh SR, et al. Vaccination of infants with meningococcal group $B$ vaccine (4CMenB) in England. N Engl J Med. 2020;382(4): 309-17.

9. Harris SL, Tan C, Andrew L, et al. The bivalent factor $\mathrm{H}$ binding protein meningococcal serogroup B vaccine elicits bactericidal antibodies against representative non-serogroup B meningococci. Vaccine. 2018;36(45):6867-74.

10. Harris SL, Zhu D, Murphy E, et al. Preclinical evidence for the potential of a bivalent fHbp vaccine to prevent Neisseria meningitidis serogroup C disease. Hum Vacc. 2011;7(Suppl):68-74.

11. Hong E, Giuliani MM, Deghmane AE, et al. Could the multicomponent meningococcal serogroup $\mathrm{B}$ vaccine (4CMenB) control Neisseria meningitidis capsular group $\mathrm{X}$ outbreaks in Africa? Vaccine. 2013;31(7):1113-6.
12. Ladhani SN, Giuliani MM, Biolchi A, et al. Effectiveness of meningococcal $B$ vaccine against endemic hypervirulent Neisseria meningitidis W strain. Engl Emerg Infect Dis. 2016;22(2):309-11.

13. Biolchi A, De Angelis G, Moschioni M, et al. Multicomponent meningococcal serogroup $B$ vaccination elicits cross-reactive immunity in infants against genetically diverse serogroup $\mathrm{C}, \mathrm{W}$ and $\mathrm{Y}$ invasive disease isolates. Vaccine. 2020. https://doi. org/10.1016/j.vaccine.2020.09.050.

14. Borrow R, Aaberge IS, Santos GF, et al. Interlaboratory standardization of the measurement of serum bactericidal activity by using human complement against meningococcal serogroup B, strain 44/76SL, before and after vaccination with the Norwegian MenBvac outer membrane vesicle vaccine. Clin Diagn Lab Immunol. 2005;12(8):970-6.

15. Santolaya ME, O'Ryan ML, Valenzuela MT, et al. Immunogenicity and tolerability of a multicomponent meningococcal serogroup B (4CMenB) vaccine in healthy adolescents in Chile: a phase $2 b / 3$ randomised, observer-blind, placebo-controlled study. Lancet. 2012;379(9816):617-24.

16. Arguedas A, Soley C, Loaiza C, et al. Safety and immunogenicity of one dose of MenACWY-CRM, an investigational quadrivalent meningococcal glycoconjugate vaccine, when administered to adolescents concomitantly or sequentially with Tdap and HPV vaccines. Vaccine. 2010;28(18): 3171-9.

17. Ram S, Lewis LA, Agarwal S. Meningococcal group W-135 and Y capsular polysaccharides paradoxically enhance activation of the alternative pathway of complement. J Biol Chem. 2011;286(10): 8297-307.

18. Biagini $M$, Spinsanti $M$, De Angelis $G$, et al. Expression of factor $\mathrm{H}$ binding protein in meningococcal strains can vary at least 15 -fold and is genetically determined. Proc Natl Acad Sci USA. 2016;113(10):2714-9.

19. Lavender H, Poncin K, Tang CM. Neisseria cinerea expresses a functional factor $\mathrm{h}$ binding protein which is recognized by immune responses elicited by meningococcal vaccines. Infect Immun. 2017;85:10.

20. Lucidarme J, Gilchrist S, Newbold LS, et al. Genetic distribution of noncapsular meningococcal group B vaccine antigens in Neisseria lactamica. Clin Vacc Immunol. 2013;20(9):1360-9.

21. Muzzi A, Mora M, Pizza M, Rappuoli R, Donati C. Conservation of meningococcal antigens in the genus Neisseria. mBio. 2013;4(3):e00163. 
22. Jongerius I, Lavender $\mathrm{H}$, Tan $\mathrm{L}$, et al. Distinct binding and immunogenic properties of the gonococcal homologue of meningococcal factor $\mathrm{H}$ binding protein. PLoS Pathog. 2013;9(8):e1003528.

23. Comanducci M, Bambini S, Caugant DA, et al. NadA diversity and carriage in Neisseria meningitidis. Infect Immun. 2004;72(7):4217-23.

24. Muzzi A, Brozzi A, Serino L, et al. Genetic meningococcal antigen typing system (gMATS): a genotyping tool that predicts $4 \mathrm{CMenB}$ strain coverage worldwide. Vaccine. 2019;37(7):991-1000.

25. Budroni S, Kleinschmidt A, Boucher P, Medini D. Pooled-sera hSBA titres predict individual seroprotection in infants and toddlers vaccinated with 4CMenB. Vaccine. 2016;34(23):2579-84.

26. Neisseria spp. PubMLST. 2020. https://www. pubmlst.org/neisseria/. Accessed 5 Oct 2020. 